\title{
Inclusión laboral de personas con discapacidades físicas, psíquicas y sensoriales en el marco de la ley 361 de 1997
} review article

\section{Occupational inclusion to people with physical, psychic and sensory disabilities within the framework of law 361 of 1997}

\author{
Lissy Natalya Luna-Ropero ${ }^{1}$ \\ Universidad del Magdalena \\ (iD) https://orcid.org/0000-0001-6998-3285
}

Resumen: El siguiente artículo tiene por objeto dar a conocer el mecanismo de inclusión laboral de las personas en condición de discapacidad mediante la ley 361 de 1997 de la república de Colombia, el cual representa fenómenos jurídicos y sociales en la contratación de personas con dificultades físicas, psíquicas y sensoriales. La ley 361 de 1997 emana el Principio de la Estabilidad Laboral Reforzada, como principio protector en la esfera laboral de las personas con discapacidad, que permite la permanencia del trabajador en el puesto de trabajo pese a su condición de discapacidad. Sin embargo, esta ley implica una barrera al momento de la vinculación laboral de dicha población. Para desarrollar el objeto de este artículo es necesario exponer el contenido y la trayectoria legislativa de la ley 361 de 1997, la protección del Estado hacia los más vulnerables y los antecedentes nacionales e internacionales de la contratación laboral de las personas con discapacidad, para luego evidenciar las consecuencias jurídicas y sociales que contrae.

Palabras clave: discapacidad; ley 361 de 1997; inclusión laboral; empresas; empleo

Recibido: 28/11/2018 | Aceptado: 13/06/2019 | Disponible en línea: 15/12/2019

Como citar este artículo: Luna-Ropero, L. (2020). Inclusión laboral de personas con discapacidades físicas, psíquicas y sensoriales en el marco de la ley 361 de 1997. Jangwa Pana 19(1), 179 - 207. DOI: https://doi.org/10.21676/16574923.3361

\begin{abstract}
The following article aims to publicize the mechanism of employment inclusion of people with disabilities through Law 361 of 1997, which represents legal and social phenomena in the hiring of people with physical, mental and sensory difficulties. The law 361 of 1997 emanates the Principle of Employment Stability, as a protective principle in the labor sphere of persons with disabilities, which allows the worker to remain in the workplace despite their disability status, taking into account the barrier that generates this same law at the time of the employment relationship of the mentioned population. In order to develop the object of the article, it is necessary to expose the content and legislative trajectory of Law 361 of 1997, the protection of the State towards the most vulnerable and the national and international antecedents of the labor contracting of persons with disabilities, to then demonstrate the legal and social consequences that it contracts.
\end{abstract}

Key words: disabilities; law 361/1997; occupational inclusion; companies; employment

\footnotetext{
${ }^{1}$ Correo Electrónico: lissyluna314@gmail.com
} 


\section{Introducción}

El panorama general de la inclusión laboral de las personas con discapacidad muestra una convergencia de procesos sociales y económicos realizados principalmente por el Estado a través de políticas públicas, así como con el apoyo de entidades privadas que pueden verse beneficiadas por el tratamiento de enfoque diferencial que implementen en el ambiente laboral. Todo esto con el fin de dar equidad a los trabajadores con necesidades especiales.

Dentro del análisis e investigación realizado para el desarrollo de este artículo se evidencia que algunas pesquisas han estudiado desde diferentes perspectivas la problemática en torno al tratamiento de la discapacidad en el trabajo, las posibles causas de la poca inclusión laboral de estas personas y las relaciones de costo beneficio a las que deben someterse empresas públicas y privadas, a fin de dar solución a los problemas de equidad que representan la discriminación de los trabajadores con condiciones especiales. Si bien la mayoría de dichos estudios se han realizado en virtud de políticas públicas de otros Estados diferentes al colombiano y respecto a mecanismos que aún no han sido implementados en el territorio nacional, los mismos permiten realizar un análisis que correlaciona los esfuerzos actuales de nuestro Estado Social de Derecho con los posibles beneficios que se obtienen cuando se implementan verdaderas políticas públicas de integración.

En primera instancia, es necesario indagar acerca del tratamiento de la discapacidad y su percepción, pasando por su contexto físico y social, y desglosar y definir las situaciones diferenciales que hacen necesario un enfoque práctico, que brinde equidad a los derechos y las necesidades de las poblaciones que poseen una diversidad. Rodríguez (2018) plantea en Nuevos significados de la discapacidad: De la igualdad de capacidades a la igualdad de derechos un enfoque metodológico cualitativo que permitió arrojar conclusiones interesantes. En primer lugar, plantea que el problema social de la discapacidad radica en la discriminación que se ejerce sobre el "colectivo", por lo que es necesario avanzar a un modelo de vida independiente que no solo se limite a la independencia física funcional, sino también a la reivindicación de la voz y el rol activo en todos los procesos y políticas públicas que tengan que ver con las personas que la poseen. En palabras de García, citado por Rodríguez (2018), "quienes mejor conocen las necesidades de las personas con discapacidad son ellas mismas, y no los profesionales". Esta suerte de autonomía moral impulsa la creación de movimientos por y para el colectivo, en donde incluso se tienen discusiones respecto a la manera como quieren ser nombrados, dándole importancia a conceptos como el de diversidad funcional para referirse a sus limitaciones. En segundo lugar, la concreción de políticas públicas y el cumplimiento de parámetros internacionales para la protección del colectivo permiten que la ciudadanía dependiente experimente un cambio de paradigma que eleve sus necesidades, intereses y derechos a una legitimidad de participación en todos los aspectos básicos de la sociedad, como la política, la economía, el entorno social, educativo, cultural y, por supuesto, laboral. Estos componentes se pueden ligar a casos y ejemplos concretos de diferentes análisis académicos que le han otorgado a la discapacidad validez fáctica en diferentes contextos nacionales y culturales, buscando la inclusión en diferentes esferas de las personas en dicha condición.

García et al. (2018) presentan una investigación cualitativa realizada en Manabí, Ecuador, que permite determinar la inclusión laboral de personas con discapacidad, en función de la inclusión social que el trabajo implica en la vida de esta comunidad. Este estudio 
analiza el enfoque de política pública y privada que vislumbra las dinámicas laborales en las que se mueven los procesos de trabajo que poseen un alto contenido social. En él se pueden evidenciar los esfuerzos realizados por el Estado ecuatoriano, concertados en políticas públicas y leyes de accesibilidad laboral que instan a los empleadores a cumplir ciertas cuotas de trabajo para personas en situación de discapacidad en empresas públicas y privadas. La investigación también hace énfasis en la urgencia que tiene el colectivo en encontrar espacios que se adapten a sus necesidades, pues, en palabras de Náñez (2012), la discapacidad surge del fracaso de un entorno social estructurado de ajustarse a las necesidades y las aspiraciones de la ciudadanía con carencias, más que de la incapacidad de esta población de adaptarse a las exigencias de la sociedad. Esto se soluciona básicamente con la adopción de medidas que equiparen las oportunidades y brinden un ambiente y una sensación total entre las personas en esta situación y las que no, elevando esa equidad en términos de vinculación, accesibilidad y permanencia en el empleo. El estudio de campo del estudio en cuestión demostró que las personas en situación de discapacidad de las Empresas Públicas de Manabí encuentran, en términos generales, apoyo en las políticas públicas implementadas por el Gobierno ecuatoriano. Sin embargo, se encuentran rodeados de un clima que, en un porcentaje del $20 \%$, recrudece sus realidades, ya sea en entornos de adaptabilidad, actividades sociales o limitaciones para el desenvolvimiento de sus labores. Por parte de los empleadores se evidenció el rechazo persistente a la contratación de personas discapacitadas, por el supuesto cobro corporativo que se debe acarrear siempre que se necesite adaptar un espacio laboral a las necesidades del trabajador, por lo que, en términos generales, la contratación se realiza de manera forzosa, para cumplir las cuotas exigidas por la ley luego de cierto número de trabajadores en situaciones regulares de desenvolvimiento físico y mental.

Por su parte, el estudio Efectos Tributarios en la Contratación de Personas con Discapacidad por parte de empresas del sector privado (Taboada, 2018) presenta una mirada clara y objetiva respecto a los beneficios económicos, sociales y tributarios que genera la contratación de personas con discapacidad, en virtud de la Ley General de la Persona con Discapacidad del Estado Peruano. Para ello, se tomaron en cuenta a las entidades que promueven la inserción laboral de las personas encuestadas, identificando como variables dos ejes principales: la facilidad para conseguir empleo y la principal limitación para las personas en esta condición. Así, se realizó finalmente una correlación costo/beneficio que permitió concluir que las empresas que integran de manera efectiva a trabajadores en condición de discapacidad obtienen beneficios tributarios altos, en virtud del modelo inclusivo de la política pública estatal. Si bien dicha tesis se realizó en Perú, en donde las condiciones de exención de impuestos y aceptación del colectivo pueden variar, muestra una radiografía detallada de la importancia de las políticas gubernamentales en el impulso de estrategias de empleo con enfoque diferencial.

Como se observa, desde dos áreas de estudio diferentes como el Trabajo Social y la Economía se pueden interpretar desde perspectivas análogas las repercusiones que se deben contemplar al momento de realizar políticas en pro de un conjunto poblacional con necesidades especiales. Esto indicaría que para la ejecución de proyectos se necesita el esfuerzo mancomunado de diferentes áreas tendientes a brindar soluciones efectivas que tengan en cuenta todas las variables, que van desde un entendimiento histórico de la importancia del trabajo en la vida del hombre, el tratamiento de la diversidad, hasta los mecanismos constitucionales, legales y jurisprudenciales que otorga en nuestro caso el Estado colombiano. De esa forma se podrá conjeturar acerca de las posibles consecuencias positivas o negativas del mecanismo estatal, y se hará una revisión de la 
idoneidad de este, a fin de determinar posibles soluciones a las problemáticas evidenciadas.

Ahora bien, centrándonos en Colombia, la ley de 361 de 1997 es el mecanismo de integración laboral de las personas que presentan discapacidades físicas, psíquicas y sensoriales. Mediante el artículo 26 de la misma ley se pretende proteger la estabilidad laboral de la persona vulnerable, dado que el precepto jurídico menciona que la discapacidad no debe ser motivo o razón para el despido, a menos que se demuestre que dicha dificultad física es incompatible e insuperable al cargo laboral.

Al efectuar un análisis sobre la ley 361 de 1997 se destacan beneficios económicos y legislativos que contrae la contratación de personas con discapacidad para las empresas y empleadores, suscribiendo al mismo tiempo aquellos intentos legislativos de reforma que ha tenido debido a la cohibición por parte de empleadores en la contratación de personas con capacidad diferencial. Esta acción es derivada de fallas interpretativas de la norma, conllevando un módulo de discriminación laboral efectivo.

Además de los fenómenos jurídicos que impiden la contratación a raíz de la ley 361 de 1997, también existen fenómenos sociales que dificultan una efectiva integración de esta población al campo laboral, como la falta de información. Los empleadores no se han planteado la idea de incluir personas con discapacidad en sus empresas por el desconocimiento de las ventajas de su contratación, trayendo como consecuencia la falta de interés, orientación y parámetros que permitan conocer el mundo de la discapacidad. Por otro lado, este artículo tiene el propósito de evidenciar que la discapacidad no solo es un problema individual de quien la padece, una barrera o limitación física, sino un problema social, debido a que las diferentes actividades humanas están diseñadas para personas sin dificultades físicas, dejando por fuera la participación de las personas en situación de discapacidad. Por tanto, la discapacidad no debe ser estudiada como una simple patología sino desde una ruptura del tejido social.

Para estructurar los fenómenos sociales y jurídicos que impiden la contratación de personas con discapacidad en el mundo laboral, fue necesario estudiar los fundamentos jurídicos nacionales e internacionales, la jurisprudencia y la doctrina correspondiente al tema, donde el Estado y la sociedad tienen el deber de integrar a las personas en condición de discapacidad y rechazar cualquier acción de discriminación contra ellos. Este artículo, entonces, pretende demostrar que las personas con discapacidad, al igual que cualquier persona sin dificultades patológicas, tienen la actitud y la aptitud para ejercer cualquier labor encomendada. Además, en el trascurso de la investigación se hace mención de aquellas cualidades laborales únicas que son características de este grupo de personas, que las representa como seres fieles, dedicados y comprometidos con el empleo.

\section{Antecedentes}

\section{El trabajo, eje fundamental para la vida del hombre}

El trabajo en la vida del hombre se desprende de la idea de que mediante este puede se adquirir el factor económico para poder sobrevivir. Sin embargo, la vida laboral es más indispensable que para cubrir las necesidades diarias: el trabajo hace parte de la naturaleza humana. El ser humano desde tiempos remotos ha visto el trabajo como eje fundamental para el desarrollo de las actividades que lo representan como ser pensante y racional, constituyéndose en una dinámica que manifiesta una satisfacción personal que repercute 
en su entorno colectivo. Por ende, su realización obedece a patrones de comportamiento que hacen mella en todas las esferas de la vida individual y comunitaria del ser humano. Engels (1975) en su libro El papel del trabajo en la transformación del mono en hombre afirma que "el trabajo ha creado al propio hombre" (p. 15). Engels realiza un estudio histórico sobre el hombre desde que se denominaba una raza de monos antropomorfos y muestra cómo trasciende la actividad laboral a través de todas sus etapas, perfeccionando el cuerpo a medida que evoluciona su necesidad de supervivencia. El autor explica que cada vez que dicha necesidad de supervivencia es más fuerte, su cuerpo y su mente va desarrollando la destreza y la habilidad de producción, por tanto, los órganos, los sentidos y las extremidades inferiores y superiores se van estructurando de acuerdo con las actividades complejas que realiza para sobrevivir. El hombre busca un objetivo para su bienestar, por ende, activa su cuerpo y mente para lograrlo.

Por el mismo lado, Marx y Engels (1970) en su ideología exponen que el trabajo es el medio de autorrealización del hombre, pues a través de este es posible que pueda saciar sus necesidades económicas y espirituales. Por medio del trabajo el hombre activa su cuerpo y mente para crear y perfeccionar. A diferencia de los animales, el hombre produce sus medios de vida para obtener su vida material. Al respecto, mencionan que:

Podemos distinguir al hombre de los animales por la conciencia, por la religión o por lo que se quiera. Pero el hombre mismo se diferencia de los animales a partir del momento en que comienza a producir sus medios de vida, paso éste que se haya condicionado por su organización corpórea. Al producir sus medios de vida, el hombre produce indirectamente su propia vida material. (p. 19)

El trabajo es la actividad en la que el hombre utiliza cuerpo y mente para un fin productivo, para transformar y crear su propia naturaleza, en la que alcanza su plena utilidad. No solo se obtienen bienes materiales, sino también felicidad, bienestar y autoestima. Por medio del trabajo el ser humano se dignifica y se complementa. Para el hombre, el trabajo es una oportunidad que abre paso a la felicidad que es obtenida por sus propios méritos.

Respecto a la necesidad del trabajo de las personas con discapacidad, en el libro Cómo ayudar a personas con discapacidad a conseguir empleo, Robert Heron (2003) señala que, como cualquier persona sin discapacidad, ellos también necesitan ganarse la vida, es decir, obtener remuneración económica producto del empleo. Además de ello, necesitan fortalecer la comunicación y las relaciones sociales, pues tener empleo evita el aislamiento social y la depresión, ayuda al fortalecimiento de las dificultades psíquicas y físicas, ya que mantenerse activo laboralmente puede contribuir como terapia (pp. 5 y 6 ). La actividad laboral produce experiencia, conocimiento, relaciones sociales y disciplina, por tanto, el trabajo es fundamental para el bienestar humano, su desarrollo y transformación. La mayor satisfacción para el hombre es ser productivo en la sociedad y que su labor sea importante para otros, solidaria y espontánea.

Mediante el trabajo, el ser humano se proyecta positivamente, ve en él la posibilidad de cumplir sus metas personales y suplir sus necesidades básicas para poder estar en un estado de tranquilidad consigo mismo. En efecto, para realizar una acción determinada, en este caso una actividad laboral, es necesario que en la persona exista conexión entre el funcionamiento del cuerpo y la mente. Por esa razón existe rechazo hacia quienes tienen 
dificultades físicas y psíquicas, ya que ante la sociedad la discapacidad es un límite para las actividades laborales.

\section{Discapacidad y sociedad}

Para definir el concepto de discapacidad es necesario analizar el concepto de deficiencia y minusvalía.

La Organización Mundial de la Salud (en adelante OMS) y la Organización Panamericana de la Salud (en adelante OPS) a través del documento "Clasificación internacional del funcionamiento, de la discapacidad y de la salud" definen la deficiencia como "la anormalidad o pérdida de una estructura corporal o de una función fisiológica. Las funciones fisiológicas incluyen las funciones mentales. Con 'anormalidad' se hace referencia estrictamente a una desviación significativa respecto a la norma estadística establecida" (2001: 231). Es decir, la deficiencia va de la mano con el cuerpo, la anatomía y lo biológico.

Por otro lado, la minusvalía es definida por la OMS y la OPS como una "situación desventajosa en que se encuentra una persona determinada, como consecuencia de una deficiencia o discapacidad que limita, impide, el cumplimiento de una función que es normal para esa persona, según la edad, sexo y los factores sociales y culturales" (2001: 137). Por consiguiente, la condición de minusvalía es la causa de una situación de deficiencia y de discapacidad.

Por último, el concepto de discapacidad es visto como un "término genérico que incluye déficits, limitaciones en la actividad y restricciones en la participación. Indica los aspectos negativos de la interacción entre un individuo (con una (condición de salud) y sus factores contextuales (factores ambientales y personales)" (Organización Mundial de la Salud y Organización Panamericana de la Salud, 2001, p. 231). Esto permite inferir que la discapacidad es algo que se tiene, más no es inherente de manera propia a una persona, por lo que un individuo no es discapacitado, más está discapacitado.

Existen diferentes tipos de discapacidad: la discapacidad física, que consiste en la ausencia o disminución de funciones motoras o físicas que impide el desplazamiento y movimiento. La discapacidad psíquica se define como aquellos trastornos que no permiten que las personas se adapten en la sociedad, como la esquizofrenia, la depresión, el autismo, entre otros. Y la discapacidad sensorial se asocia al funcionamiento de los órganos de los sentidos, como la vista, el oído y el lenguaje.

Asumiendo el concepto de la discapacidad con respecto a "la capacidad de realizar una actividad en la forma o dentro del margen considerado normal para el ser humano" de la Organización Mundial de la Salud, ¿es la discapacidad un problema individual de quien la padece o es un problema social?

En los años ochenta en Estados Unidos y Reino Unido se dio un movimiento llamado "el modelo social de la discapacidad", promovido por Michael Oliver. Dicho movimiento dio un enfoque sociológico a la problemática de la discapacidad, es decir, dejó de ser un problema médico para convertirse en una dificultad social y política. Mediante este movimiento, Oliver (1996), citado por Barton (2006), expuso que la discapacidad no era un problema individual, sino una dificultad social: "la discapacidad no era resultado de una patología física, sino de la organización social” (p. 110). En otras palabras, la 
sociedad tenía patrones y actividades en las cuales las personas en situación de discapacidad no tenían participación. Este enfoque iba en contra de la opinión médica, ya que este movimiento afirmaba que las causas de la incapacidad eran los estereotipos sociales y no los problemas biológicos que las personas padecían.

A partir del Modelo Social de la Discapacidad se insertaron conceptos imprescindibles que favorecen el enfoque de Michael Oliver, que distinguen las dificultades médico biológicas y los perjuicios sociales. El concepto de la discapacidad y el impedimento, definidos por la Unión de Impedidos Físicos contra la Segregación (UPIAS), citada por Barton (2006), manifiesta que "el impedimento es la falta de parte o de todo un miembro, órgano o mecanismo corporal deficiente" y, por el contrario, "la discapacidad [es el] perjuicio o restricción de la actividad causada por una organización social contemporánea que ignora o completa parcialmente a las personas con impedimentos físicos, y por tanto las excluye de las principales actividades sociales".

Dados los conceptos anteriores, la discapacidad se ve inmersa en la sociedad al crear una esfera negativa y de prejuicios para esta población que intenta adaptarse a las actividades diarias. Por tanto, cuando las personas en condiciones de discapacidad obtienen apoyo y solidaridad en la sociedad a través de la educación y fomento de empleo, tienen más posibilidades de adaptación y desenvolvimiento en el desarrollo de las actividades que permiten su autorrealización.

$\mathrm{Al}$ respecto, la Corte Constitucional se ha pronunciado, identificando las repercusiones sociales que rodean los efectos de la discapacidad en cada individuo, argumentando que los efectos de la discapacidad sobre una persona dependen de manera fundamental del entorno social, es decir, que la discapacidad no es únicamente un problema individual. Esto significa que

un medio social negativo y poco auspiciador puede convertir la discapacidad en invalidez, y que, por el contrario, un ambiente social positivo e integrador puede contribuir de manera decisiva a facilitar y aliviar la vida de las personas afectadas con una discapacidad. (Corte Constitucional, 2013, Sentencia C-066)

La sociedad en la vida de la persona que padece una discapacidad tiene un papel muy importante, dado que es el impulso o freno para su vida personal, pues ser aceptado puede ser un verdadero reto cuando en el mundo existe la discriminación.

La discriminación contra las personas con discapacidad es definida por la Convención Interamericana para la Eliminación de todas las Formas de Discriminación así:

Toda distinción, exclusión o restricción basada en una discapacidad, antecedente de discapacidad, consecuencia de discapacidad anterior o percepción de una discapacidad presente o pasada, que tenga el efecto o propósito de impedir o anular el reconocimiento, goce o ejercicio por parte de las personas con discapacidad, de sus derechos humanos y libertades fundamentales. (1999:3)

Así mismo, la sociedad y las convenciones pueden seguir definiendo la discapacidad como sinónimo de impedimento o barrera física, sin embargo, surge la duda del origen de esas barreras, si sus creaciones son por sí solas y si están destinadas a ser desventaja para la persona con discapacidad. El texto de investigación jurídica Posición de la 
discapacidad: los aportes de la convención, de Patricia Brogna (2010), hace una crítica hacia las convenciones y los tratados internacionales. Este expone la situación de la discapacidad sujeta a la estructura de la sociedad, es decir, la misma sociedad ha suplido sus necesidades conforme a su naturaleza, dejando por fuera la discapacidad. Por tanto, la discapacidad debe ser estudiada junto a la sociedad y no individual, ya que es la misma sociedad quien impone las barreras.

Respecto a las convenciones, comenta que estas instituciones globales no asocian el concepto con la realidad de una persona en situación de discapacidad. La discapacidad es una dificultad que le compete a todo el conglomerado social y no solo a quien la padece, por tal razón, estas personas deben ser incluidas en todas las actividades humanas y no ser catalogadas como anormales por la sociedad.

\section{Protección constitucional de la discapacidad}

Colombia es un Estado Social de Derecho, lo que implica que sus instituciones están bajo los parámetros del ordenamiento constitucional. Las autoridades y la sociedad deben actuar acorde a estos, y en ellos el hombre debe gozar de su dignidad. Para esto se necesita que el Estado brinde condiciones sociales, económicas, culturales y educativas para el pleno desarrollo de sus capacidades como persona humana. Respecto a lo anterior, en la Sentencia T-1095 de 2004, la Corte reitera que dentro de los parámetros del Estado Social de Derecho las autoridades deben velar por el bienestar de las personas que se encuentran en situación de debilidad manifiesta por razón de su condición económica, física o mental, y que, por tanto, el Estado y la sociedad deben adoptar medidas necesarias para la integración e igualdad social para esta población (Corte Constitucional, 2004 Sentencia T-1095).

De la mano se encuentra el artículo 47 de la Constitución Política donde establece que "El Estado debe adelantar una política de previsión, rehabilitación e integración social para aquellos que tienen disminuidas sus capacidades físicas, sensoriales y psíquicas, a quienes se les debe brindar la atención especializada que necesiten" (Const., 1991, art. 47). De ello se destaca que el Estado, a través del ordenamiento y las políticas públicas, debe garantizar la protección, la salud y la inclusión social a las personas con discapacidad, de tal modo que permitan el normal desarrollo y el desenvolvimiento en la sociedad.

El artículo 53 de la Constitución Política afirma que "La Carta prevé como uno de los principios mínimos que debe orientar las relaciones laborales, es la estabilidad en el empleo y la garantía de la seguridad social" (Const., 1991, art. 53). De manera análoga, la Sentencia T-519 de 2003 expone el Principio de Estabilidad Reforzada, el cual se explica cómo fundamental para quienes se encuentran en estado de debilidad manifiesta. Además, contempla que el mecanismo de defensa idóneo cuando se es vulnerado es la Tutela, sin embargo, se debe demostrar la conexidad entre la condición de debilidad manifiesta y la desvinculación del empleo, que haya dado lugar a la discriminación laboral (Corte Constitucional, 2003, SentenciaT-519).

Por último, la Carta presenta el artículo 54 de la Constitución Política que expone

Es una obligación del Estado y de los empleadores ofrecer formación y habilitación profesional y técnica a quienes lo requieran. El Estado debe propiciar la ubicación laboral de las personas en edad de trabajar y garantizar a los 
minusválidos el derecho a un trabajo acorde con sus condiciones de salud. (Const., 1991, art. 54)

De ahí, en la sentencia T-434 de 2008, la Corte manifiesta que a los empleadores no solo se les prohíbe despedir al trabajador por razón de su debilidad manifiesta, sino que también tienen la obligación de reubicarlo en un puesto de trabajo en donde pueda ejercer funciones laborales sin alterar su salud. (Corte Constitucional, 2008, Sentencia T-434).

Una vez analizado el articulado de la Constitución Colombiana que expone la protección, las garantías y los derechos fundamentales de quienes padecen alguna anomalía física, sensorial o psíquica, es trascendental mencionar que existen disposiciones internacionales de las que el Estado es parte y se encuentra en la obligación de cumplir. A pesar de no encontrarse en las normas nacionales, estas se encuentran indexadas al bloque de Constitucionalidad.

\section{Protección a la discapacidad mediante convenios y tratados internacionales}

El bloque de constitucionalidad supone la existencia de disposiciones normativas que, sin abordarse tácitamente, son incluso de igual rango Constitucional. La sentencia C- 255 de 1995 define el bloque de Constitucionalidad como

El bloque de constitucionalidad está compuesto por aquellas normas y principios que, sin aparecer formalmente en el articulado del texto constitucional, son utilizados como parámetros del control de constitucionalidad de las leyes, por cuanto han sido normativamente integrados a la Constitución, por diversas vías y por mandato de la propia Constitución. Son pues verdaderos principios y reglas de valor constitucional, esto es, son normas situadas en el nivel constitucional, a pesar de que puedan a veces contener mecanismos de reformas diversas al de las normas del articulado constitucional stricto sensu. (Corte Constitucional, 1995, Sentencia C-255)

Mediante el bloque de Constitucionalidad, existen Convenios y Tratados Internacionales que consagran principios especiales que promueven la protección y el respeto de las personas en condiciones de discapacidad, con relación a sus derechos laborales, igualdad de condiciones e integración en la sociedad. El Estado colombiano es parte de los presentes convenios, por tanto, está en la obligación de salvaguardar a este grupo de personas y rechazar cualquier tipo de discriminación contra ellas.

La Declaración Universal de Derechos Humanos, adoptada por la Asamblea General de las Naciones Unidas el 10 de diciembre de 1948, se constituye en un elemento fundamental de todo tipo de categorías de derechos humanos. Incluso el derecho al trabajo hace parte de la segunda categoría entre los derechos económicos sociales y culturales, que alude a que todas las personas, más allá de obtener un cargo laboral, tienen derecho al acceso laboral sin discriminación, a la libertad profesional y a la escogencia de empleo. En su artículo 23. la Declaración Universal estipula que todas las personas tienen derecho a un trabajo de su preferencia y profesión, a tener un trabajo en condiciones dignas, reglamentado por la ley y respetando los derechos del trabajador (Declaración Universal de los Derechos Humanos, 1948).

La Convención sobre los Derechos de las Personas con Discapacidad adoptada por la Asamblea de las Naciones Unidas en diciembre de 2006, en el artículo segundo explica 
de forma general la discriminación hacia las personas con discapacidad, la cual limita y obstaculiza el acceso de esta población a la educación, salud y trabajo. Los Estados parte y la sociedad deben ser incluyentes de todas las personas, sin importar su dificultad física, intelectual o sensorial, y garantizarles la igualdad de condiciones en temas políticos, económicos, educativos y laborales (Convención sobre los derechos de las personas con discapacidad, art. 2).

Así mismo, la Convención manifiesta en el artículo cuarto "Tomar todas las medidas pertinentes para que ninguna persona, organización o empresa privada discrimine por motivos de discapacidad" (Convención sobre los derechos de las personas con discapacidad, 2006, art. 4 literal e). Por consiguiente, los empleadores no deben obstruir el vínculo laboral que tiene el trabajador con la empresa por razones de salud o discapacidad.

Las personas con discapacidades físicas, psíquicas o sensoriales tienen aspiraciones laborales como cualquier persona, las cuales se abastecen mediante la educación para demostrar sus capacidades en cualquier cargo que se le encomiende. Los Estados parte, mediante la Convención sobre los Derechos de las Personas con Discapacidad, en el artículo 27, se acogen a que se deben garantizar las oportunidades de empleo y educación, ya que a partir de estas es posible la habilitación y el desenvolvimiento positivo de las personas en condición de discapacidad en la sociedad (Convención sobre los derechos de las personas con discapacidad, 2006, art. 27).

En cuanto a las Normas Uniformes sobre la Igualdad de Oportunidades para las Personas con Discapacidad, aprobado por la Asamblea General de las Naciones Unidas en marzo de 1994, con relación al artículo 7 y 26, expresa que los Estados parte deben brindar oportunidades de empleo a las personas con discapacidad, sin importar la ubicación rural o urbana. La protección no tiene límite dentro del territorio, por tanto, donde se encuentren deben adquirir salubridad, educación, empleo y facilidad de acceso a los servicios públicos (Normas Uniformes sobre la Igualdad de Oportunidades para las Personas con Discapacidad, 1994).

Los Estados parte, mediante las disposiciones legales, convenios y tratados internacionales, deben velar por el bienestar de las personas en situación de discapacidad, de modo que creen estrategias o programas de apoyo para que esta población adquiera formación laboral, capacitación y orientación. En este sentido, el Convenio sobre la Readaptación Profesional y Empleo del año 1983 (NUM 159), en su artículo 7 expresa que las autoridades deben facilitar el acceso de las personas con discapacidad con el fin de realizar las actividades comunes sin dificultad, y que con respecto al empleo estas puedan adaptarse en el medio laboral y permanecer en el cargo sin contradicciones (Convenio sobre la readaptación profesional y empleo, 1983).

Finalmente, es notorio que la discapacidad es un cometido para la comunidad, tanto autoridades, como empleadores y sociedad. Por tal razón, la inclusión laboral y la igualdad de oportunidades no se deben quedar en el escrito de un convenio o constitución, sino que todos los principios, derechos y deberes deben verse reflejados en la realidad social. 


\section{Fenómenos sociales que impiden la contratación de personas en condiciones de discapacidad}

Habiendo estudiado los fundamentos jurídicos nacionales e internacionales que desarrollan el sustento legal y jurisprudencial que envuelven los derechos de las personas en condición de discapacidad, es menester ahondar en el tema que nos atañe en este artículo. Por eso, es necesario estudiar los fenómenos sociales que impiden la contratación de personas en condiciones de discapacidad. Según el libro La perspectiva del mundo empresarial, respecto a la contratación de personas con discapacidad, con base en los estudios empresariales, la mayor causa de la no contratación de personal discapacitado es la falta de información e instrucción.

La falta de información y el hecho de que sea difícil encontrar a personas con discapacidad adecuadas al puesto de trabajo se configuran como los principales factores que hacen más compleja la contratación de personas con discapacidad en comparación con otros colectivos. (Fundación ONCE y Manpower, 2008: 34).

Respecto al análisis, los empresarios se encuentran poco informados sobre el mundo de la discapacidad y de la normatividad, beneficios, contratación, etc. Además de ello, se deduce que los perfiles que exigen las empresas para sus trabajadores son excluyentes para las personas en condiciones discapacidad, siendo estrechas las oportunidades de empleo.

(...) las empresas que no se han planteado la contratación de personas con discapacidad no barajan la posibilidad de contratar a personal con discapacidad porque acudiendo a las bolsas habituales de empleo (que suponen su opción prioritaria) han visto cumplidas sus expectativas y han cerrado con éxito los procesos de selección que intentaban cubrir. De este modo, su demanda de candidatos está cubierta con la oferta actual, sin necesidad de recurrir al colectivo de personas con discapacidad. (Fundación ONCE y Manpower, 2008: 44)

Es cierto que los empleadores, para mejorar la producción de sus empresas, buscan personal con cualidades y perfiles ideales para el cargo que necesitan, y también es evidente que no hay razón para acudir a la contratación de personal discapacitado cuando existen personas con todas las capacidades y sin limitación física. Sin embargo, independiente de los beneficios que brinda el Estado, la contratación de personal discapacitado en una responsabilidad social.

Por otro lado, Heron (2003), en el capítulo "Obstáculo para el empleo", resalta que las personas con discapacidad se enfrentan a infinidades de obstáculos en la sociedad, entre ellos las actitudes negativas y discriminatorias de la comunidad, el acceso desigual a la educación y la formación, las instalaciones y el transporte inaccesibles, la falta de información y la falta de servicios de asistencia y apoyo para la discapacidad. Como consecuencia de ello, este grupo de personas es excluido de las actividades diarias, teniendo una participación limitada en la sociedad.

No cabe duda [de] que la intención de favorecer la integración social de las personas con discapacidad está presente en la intención de contratación, pero en muchos casos, sin el empuje que supone la obligación legal o los beneficios económicos y fiscales, la posibilidad de incorporar a personas con discapacidad a la plantilla de las empresas no se plantearía como alternativa. Dicho de otra forma, 
la colaboración con la integración es una consecuencia, un extra, que se deriva de un proceso que se inicia, en muchos casos, por la necesidad/conveniencia de cumplir con la legislación o por el interés de los beneficios que se obtienen. (Fundación ONCE y Manpower, 2008: 40)

Por tanto, debería ser un deber social la inclusión de personal discapacitado a la esfera laboral y no una obligación legislativa o interés económico. La solidaridad y apoyo hacia los más vulnerables es responsabilidad de todos los colombianos. Es una obligación respetar y proteger la dignidad humana de las personas en condiciones de discapacidad.

\section{Principio de la Estabilidad Laboral Reforzada}

Si bien el concepto de la Estabilidad Laboral Reforzada no está contenido en la normatividad, este principio es comprendido por la jurisprudencia orientada al derecho fundamental de la protección laboral del trabajador, como se consagra en el artículo 53 de la Constitución Política de Colombia. La Corte Constitucional en Sentencia T-317 de 2017 la define como,

parte integral del derecho constitucional al trabajo y las garantías que se desprenden de éste, la cual se activa cuando el trabajador se encuentra en situación de vulnerabilidad, debido a condiciones específicas de afectación a su salud, su capacidad económica, su rol social, entre otros. Dicha estabilidad se materializa en la obligación impuesta al empleador de mantenerlo en su puesto de trabajo en razón de su condición especial. (Corte Constitucional, 2017, Sentencia T-317)

Así mismo, esta corporación en Sentencia Unificada 256 de 1996 expresa que dicha protección cubre a las personas más vulnerables en la sociedad que padecen alguna afectación física, psíquica y sensorial, por tanto, el Estado está en la obligación de salvaguardar las condiciones de vida de este grupo de personas, pues "son sujetos de protección especial por nuestro Estado Social de Derecho, los discapacitados, los minusválidos, las mujeres embarazadas, los enfermos de VIH, madres cabeza de familia y padres cabeza de familia, entre otros" (Corte Constitucional, 1996, Sentencia SU 256). Con respecto a las personas que sufren discapacidad, la Corte Constitucional en Sentencia C-531 de 2000 menciona que las que personas que se encuentren afectadas de salud o padezcan una limitación, ya sea dentro de la zona laboral o por fuera, no podrán ser despedidas luego de haber adquirido dicha limitación física. Es decir que este principio garantiza la permanencia del trabajador en la empresa luego de padecer algún quebranto en su salud. Por tal razón, el empleador debe brindar apoyo a la persona que ha sufrido una anomalía y reubicarlo en otro puesto en el que pueda desarrollar mejor sus funciones laborales si es necesario (Corte Constitucional, 2000, Sentencia C-531).

En otras palabras, doctrinantes como Pérez, definen la Estabilidad Laboral Reforzada como

la representación constitucional derivada de un fuero, que genera en cabeza del empleador la carga procesal sobreviniente del principio de solidaridad, de continuar el vínculo laboral de manera independiente al tipo de contrato, hasta tanto exista una causa legal y no obtenga el permiso del inspector del trabajo para dar por terminado o hacer efectiva la culminación del contrato de trabajo. (2016: 146) 
En síntesis, el Principio de la Estabilidad Reforzada es la garantía en la cual el empleador no podrá por voluntad propia interrumpir las actividades laborales del trabajador por causa de su condición física, psíquica o sensorial, dejándolo en condiciones de desempleado. El trabajador podrá conservar su empleo hasta que la oficina de trabajo dé autorización del despido.

\section{Mecanismo de integración laboral, ley 361 de 1997 bajo el principio constitucional de la Estabilidad Laboral Reforzada}

En Colombia esta protección está vigente en la política nacional y se regula a través de la ley 361 de 1997, en la cual se establecen mecanismos de integración laboral a personas en condiciones de discapacidad. El Estado colombiano, mediante sus entidades de responsabilidad social, tiene el deber de incluir a las personas en condición de discapacidad en la sociedad, con el fin de que desarrollen sus habilidades a través de las oportunidades de educación y empleo. Así, en su articulado expone que

En ningún caso la limitación de una persona podrá ser motivo para obstaculizar una vinculación laboral, a menos que dicha limitación sea claramente demostrada como incompatible e insuperable en el cargo que se va a desempeñar. Así mismo, ninguna persona limitada podrá ser despedida o su contrato terminado por razón de su limitación, salvo que medie autorización de la oficina de Trabajo. (Ley 361, 1997)

Respecto de lo observado, referentes jurisprudenciales determinan, entre otros argumentos que

(...) despedir a una persona en estado de discapacidad sin autorización del Ministerio del Trabajo, es un acto que tiene consecuencias identificables, como lo son: (i) que el despido sea absolutamente ineficaz, (ii) que en el evento de haberse presentado éste, corresponde al juez ordenar el reintegro del afectado y que, (iii) sin perjuicio de lo dispuesto, el empleador desconocedor del deber de solidaridad que le asiste con la población laboral con discapacidad, pagará la suma correspondiente a 180 días de salario, a título de indemnización, sin que ello signifique la validación del despido. (Corte Constitucional, 2011, Sentencia T021)

Despedir a la persona en condiciones de discapacidad trae como resultado un hecho más desfavorable para ella, como la alteración del estado de su salud y la desprotección sin sustento económico para lidiar con ello. Por ende, el Gobierno colombiano protege a las personas que se encuentran en debilidad manifiesta no desamparándolas y garantizando que aun después del lamentable hecho que originó la discapacidad este pueda seguir ejerciendo su vida laboral.

(...) para que un trabajador acceda a la indemnización estatuida en el artículo 26 de la Ley 361 de 1997, se requiere: (i) que se encuentre en una de las siguientes hipótesis: a) con una limitación "moderada", que corresponde a la pérdida de la capacidad laboral entre el $15 \%$ y el $25 \%$, b) "severa", mayoral $25 \%$ pero inferior al $50 \%$ de la pérdida de la capacidad laboral, o c) "profunda" cuando el grado de minusvalía supera el $50 \%$; (ii) que el empleador conozca de dicho estado de salud; y (iii) que termine la relación laboral "por razón de su limitación física" y sin 
previa autorización del Ministerio de la Protección Social. (Corte Suprema de Justicia, Sala de Casación Laboral, R. 3754, 2010)

Del mismo modo,

(...) tal protección no sólo se debe garantizar al trabajador que se encuentra en situación de discapacidad. También se hace extensivo a quienes tienen limitaciones físicas, psíquicas o sensoriales. A estas personas se les debe brindar asesoría y seguimiento para afrontar las condiciones derivadas de la pérdida $\mathrm{o}$ merma de la capacidad laboral. En cumplimiento de ello, al empleador le asiste el deber de reubicar al trabajador en un puesto de trabajo que le permita maximizar su productividad y alcanzar su realización profesional, de tal forma que quienes se encuentran con limitaciones a causa de su salud logren aumentar el rendimiento y se fomente la solidaridad. (Corte Constitucional, 2017, Sentencia T-317)

\section{La ley 361 de 1997 y la contratación de personas en condición de discapacidad}

A pesar de que Colombia a través de sus disposiciones promueve las oportunidades de empleo a las personas en condiciones de discapacidad mediante la ley 361 de 1997, jurisprudencia y convenios internacionales otorgando derechos y protección a lo más vulnerables, esta misma protección ha causado que las empresas y empleadores se cohíban de contratar a personas con este grado de dificultad, por temor a entorpecer su habilitación y desarrollo o por las disposiciones jurídicas que establece la legislación al momento de contratar o darle fin al contrato laboral.

La Sentencia T-271 de 2012, que reiteró que, el derecho a la protección laboral reforzada cobija, equitativamente, tanto a los trabajadores que padecen un deterioro en su salud, que limita la ejecución de sus funciones, como a quienes se encuentran en condición de discapacidad. De tal forma que, al proceder a la terminación de sus contratos o relación laboral sin previa autorización del Ministerio del Trabajo se vulneran sus derechos a la igualdad y al trabajo como formas de lograr la adecuada integración social dispuesta en la Constitución (Corte Constitucional, 2012, Sentencia T-271).

De modo que los empleadores, para evitar esta problemática con el Ministerio de Trabajo y las consecuencias jurídicas que contrae el despido de los trabajadores en condiciones de discapacidad, se rehúsan a contratar o fomentar empleo para este grupo de personas.

El Ministerio de Trabajo ante tal circunstancia tiene la facultad de ceder la autorización al empleador, siempre y cuando este pueda demostrar la incompatibilidad del discapacitado en el cargo, es decir, que respecto a las justas causales del articulo 62 en el literal A-13 donde menciona "la ineptitud de trabajador para cumplir las funciones laborales" (Código Sustantivo del Trabajo, 1950), serán sometidas las razones a evaluación del Ministerio en cuanto a la condición de discapacidad del trabajador.

El Ministerio del Trabajo únicamente tiene competencia para autorizar la terminación de un vínculo contractual a una Empresa, Empleador o una Cooperativa o Pre cooperativa de Trabajo Asociado cuando motive la condición de discapacidad de un trabajador, es decir, cuando dicha limitación sea considerada como incompatible o insuperable con los cargos existentes del 
interesado, no obstante el esfuerzo del solicitante para realizar la reubicación o incluso la reconversión de mano de obra de la persona según el caso. Lo anterior, implica que dentro del procedimiento únicamente se evalúa, cuando en materia laboral se trate, la causal contemplada en el literal A-13 del artículo 62 del C.S.T. Para todos los casos, el referente será la ineptitud del trabajador para realizar sus funciones, teniendo en cuenta el grado de disminución de su condición física y su pérdida de capacidad laboral. (Corte Constitucional, 2008, Sentencia T-812)

Dado lo anterior, el Ministerio de Trabajo solo se limita a estudiar las solicitudes de aquellos empleadores que demuestren que dicha discapacidad física es incompatible e insuperable para el cargo laboral, no entrometiéndose en las demás justas causales que establece el artículo 62 de Código Sustantivo del Trabajo. Manifiesta que, de existir una justa causal diferente a la del literal A-13, el solicitante puede acudir a la jurisdicción laboral ordinaria para ejercer su derecho del debido proceso.

Por otro lado, la sentencia T-198 de 2006 reflexiona sobre el artículo 26 de la ley 361 de 1997 y comenta que esta disposición tiene una parte positiva y una negativa en cuanto a la protección de la persona en condiciones de discapacidad.

El artículo 26 de la Ley 361 de 1997 consagra, así mismo, lo que puede denominarse protección laboral reforzada positiva y negativa, a favor de las personas con discapacidad. En el campo positivo, establece que la limitación de una persona, no podrá ser motivo para obstaculizar una vinculación laboral, a menos que dicha limitación sea claramente demostrada como incompatible e insuperable en el cargo que se va a desempeñar. De otra parte, dentro de lo que puede denominarse protección laboral negativa, la ley 361 de 1997 ordena que ninguna persona limitada podrá ser despedida o su contrato terminado por razón de su limitación, salvo que medie autorización de la oficina de Trabajo. (Corte Constitucional, 2006, T-198)

El análisis que hace la Corporación en la anterior providencia reflexiona que artículo 26 de la ley 361 de 1997 tiene aspectos positivos en cuanto a la no discriminación laboral de las personas en condiciones de discapacidad, pero a la vez una parte negativa hacia los empleadores al momento de desvincular el trabajador que ha finalizado el contrato o prestación laboral, siendo así este un fenómeno social y jurídico, ya que la no contratación de personal discapacitado es por causa de una ley que va a favor de la no discriminación, la inclusión laboral y permanencia de los mismos.

La norma incentiva a los empresarios a la inclusión laboral de personas en condición discapacidad en sus empresas, pero a su vez la condena a no terminar el vínculo laboral si el trabajador con discapacidad incumple una obligación o si su contrato ha terminado. Por el contrario, tendrá altas indemnizaciones a favor de la persona vulnerable. Esto ha ocasionado que la propia norma que protege se haya convertido en barrera para las personas con limitación y prejuicio para los empleadores.

El mandato constitucional habla de igualdad de derechos y oportunidades para todos y de protección especial para los grupos más vulnerables. Mal podría el legislador propiciar protección indebida a los trabajadores cuyo bajo o nulo desempeño no tenga relación alguna con la situación de discapacidad que le afecte. Es claro que, si un empleador contrata una persona en situación de discapacidad, 
lo hace a sabiendas de que esa incapacidad no le impedirá cumplir con las funciones para las cuales ha sido contratado y que podrá hacer su trabajo en igualdad de condiciones que los demás trabajadores. De no ser así, y de existir normas que le obliguen a dar un tratamiento preferencial y con alta discriminación positiva, seguramente ningún empresario ofrecería posibilidades laborales a las personas en situación de discapacidad. (Proyecto de ley 129, 2008)

El anterior proyecto de ley analiza las consecuencias jurídicas que contrae la ley 361 de 1997, por el conflicto jurídico que, como resultado, genera que los empleadores se abstengan de contratar personal con discapacidad, puesto que no se tiene claridad de los límites de protección que brinda la norma al momento de su aplicación. Este conflicto normativo genera que ambas partes estén en desventaja y, lejos de amparar este tipo de trabajadores, lo que crea es una barrera.

Por otro lado, la sentencia C-744 del 2012 donde se demanda el artículo 137 del decreto ley 19 de 2012 que deroga el artículo 26 de la ley 361 de 1997, el cual conservó la redacción original, solo agrega que no se requerirá autorización previa del Ministerio de Trabajo cuando el trabajador incurra en alguna de las causales justas para dar por terminado el contrato de trabajo. Sin embargo, la Corte Constitucional, mediante la presente providencia, la declara inexequible, dado que el Presidente de la República, en sus facultades extraordinarias, no está facultado para regular sobre una norma antitrámites de dicha temática. Por tanto, se declara la situación como inconstitucional

Para la Corte, acertaron los demandantes al señalar dentro de su argumentación, que el Presidente de la República al expedir el artículo 137 del Decreto Ley 19 de 2012, excedió los límites de las facultades que le fueron conferidas por el artículo 75 de la Ley 1474 de 2011, desconociendo así lo estatuido en el numeral $10^{\circ}$ del artículo 150 superior (...) normas con fuerza de ley para suprimir o reformar regulaciones, procedimientos y trámites innecesarios existentes en la Administración Pública. (Corte Constitucional, 2012, Sentencia C-744).

Más adelante, el 27 de junio del año 2015, se expidió un nuevo proyecto de ley, el 018 de 2015 del Senado a favor de las personas en condiciones de discapacidad, con el objeto de establecer medidas que permitieran el acceso laboral. Mediante este se requiere adicionar al Código Sustantivo del Trabajo, en el Titulo III, un tema referente a los contratos de trabajo con determinados trabajadores. Este contiene reajustes en razón a los despidos de personal discapacitado.

Artículo 103B. Terminación del contrato de trabajador con discapacidad. Los contratos de trabajo se rigen por las normas del presente Código y las que lo adicionan y modifican. Para la terminación del contrato de un trabajador con discapacidad, se adicionan las siguientes reglas:

1. Ninguna persona con discapacidad podrá ser despedida o su contrato terminado por razón de su limitación, salvo que medie autorización de la oficina de Trabajo.

2. Sin perjuicio de lo establecido en el numeral anterior, no se requerirá de autorización por parte del Ministerio del Trabajo cuando el trabajador con discapacidad incurra en alguna de las causales establecidas en la ley como justas causas para dar por terminado el contrato. 
3. Para la terminación del contrato de trabajador con discapacidad siempre se garantizará el derecho al debido proceso, teniendo en todo momento en cuenta la discapacidad de trabajador. (Proyecto de Ley 018, 2015)

El mencionado proyecto de ley tiene como objeto que el trabajador en condiciones de discapacidad tenga un trato como cualquier otro trabajador. Entonces, no se requerirá la autorización del Ministerio de Trabajo para darle fin al vínculo laboral y, así, al momento en que incurra en las justas causas para dar por terminado el contrato establecidas en el artículo 62 de Código Sustantivo del Trabajo este podrá ser desligado del cargo, pero sin perder la protección que ampara el despido por razón de su limitación. Es decir, en cuanto a igualdad de condiciones, los trabajadores deben someterse a lo establecido en la ley cuando cometan alguna falta y no se tendrá preferencia a las personas en condiciones de discapacidad en estos casos.

Respecto a la reforma del Código Sustantivo del Trabajo, en el Titulo III, varias instituciones importantes que guardan relación con la contratación laboral y la discapacidad presentaron sus respectivas consideraciones, entre ellas el Consejo Gremial Nacional que expresó total acuerdo con el proyecto, ya que como organización económica del sector privado está en pro de la inclusión laboral a personal discapacitado a las empresas. Este expone que el anterior proyecto se rige bajo el principio de la buena fe, en donde todas las actuaciones y gestiones ejercidas por los particulares se presumen honestas y transparentes. Por ello, la eliminación de uno de los requisitos incentiva al campo empresarial al fomento de empleo y acceso laboral a personas en condiciones de discapacidad.

Desde el sector empresarial se ha identificado que la pluralidad de requisitos necesarios para la desvinculación de un trabajador en condición de discapacidad puede desincentivar su contratación. De esta manera, la eliminación de uno de los requisitos existentes puede tener efectos positivos en los índices de contratación de estas personas. En este contexto, el Proyecto da aplicación al Principio de Buena Fe en la terminación del contrato laboral con un trabajador en condición de discapacidad y propende por la racionalización de trámites dentro del Estado. (Consejo Gremial Nacional, 2015)

Por otro lado, la fundación Fundown Caribe, organización privada sin ánimo de lucro, líder y protectora de la calidad de vida de las personas con Síndrome de Down, declara estar de acuerdo con la aprobación de la ley 018 de 2015, dado que su fundamento es novedoso en cuanto a las garantías para la inclusión laboral, sin dejar a un lado la protección constitucional que consagra la ley 361 de 1997.

Consideramos que el Proyecto de ley 018 es novedoso al proponer integrar al Código Sustantivo del Trabajo las reglas que garantizan la protección laboral de las personas con discapacidad y a la vez informar de manera clara y precisa a los empleadores sobre la manera de hacer efectiva dicha protección, con el objeto de que la inclusión laboral de las personas con discapacidad sea real y efectiva. (Fundown Caribe, 2015).

Otro pronunciamiento importante es el de la Organización Sindical Sintrametal que expresa inconformismo y desacuerdo con la aprobación de la ley 018 de 2015. Ella 
comenta que entre sus afiliados se encuentran trabajadores en condiciones de discapacidad que durante años han trabajado inalcanzablemente en sus diferentes campos, obteniendo un excelente rendimiento, por tanto, no es justo para el trabajador enfermo que el empleador rompa el principio de solidaridad al despedirlos quedando en condiciones más desfavorables. Manifiesta que no es necesario el reajuste, dado que la misma ley 361 de 1997 en el artículo 26 en ningún momento prohíbe el despido de las personas en condiciones de discapacidad, por el contrario, permite que previa autorización del Ministerio de Trabajo, se confiera el debido proceso, mediante el cual el empleador puede dar a conocer los argumentos válidos para dar por terminado el contrato laboral.

No hay que olvidar que los empleadores sí pueden despedir a un trabajador enfermo, solicitando el permiso al Ministerio del Trabajo, donde trabajador y empleador puedan presentar sus argumentos, debiendo la autoridad garantizarles el debido proceso y el derecho de defensa, mecanismo que se pretende eliminar por el proyecto citado. (Sintrametal, 2015).

El proyecto de ley 018 de 2015, al igual que otros intentos legislativos por reformar el artículo 26 de la ley 361 de 1997, como se puede observar, no ha tenido un desarrollo positivo, quedando en el total olvido la necesidad laboral del discapacitado y por tanto el archivo del proyecto.

En efecto, después del anterior estudio del artículo 26 de la ley 361 de 1997, de los intentos legislativos por reformarla junto a las diferentes consideraciones y las limitaciones que tienen las empresas para contratar personal discapacitado, es importante destacar que en el contenido de la norma no existe mandato que prohíba el despido de personas en condiciones de discapacidad,

En ningún caso la limitación de una persona podrá ser motivo para obstaculizar una vinculación laboral, a menos que dicha limitación sea claramente demostrada como incompatible e insuperable en el cargo que se va a desempeñar. Así mismo, ninguna persona limitada podrá ser despedida o su contrato terminado por razón de su limitación, salvo que medie autorización de la oficina de Trabajo. (Ley 361, 1997, Subrayado fuera del texto.)

El artículo 26 de la ley 361 de 1997 como normatividad que incentiva la inclusión laboral y la estabilidad laboral reforzada del discapacitado, está en contra de aquellos sucesos jurídicos y sociales que impiden la contratación laboral y que como consecuencia generan discriminación, no de aquellas justas causas que incurre el trabajador dentro de sus funciones laborales que genera despido unilateralmente por empleador establecidas en el artículo 62 de Código Sustantivo del Trabajo. Por ende, la esencia de la norma solo se limita a proteger al trabajador cuando sea excluido por su condición de discapacidad y no por el incumplimiento de las obligaciones laborales.

\section{Beneficios e incentivos para las empresas que contraten personas en condición de discapacidad}

La ley 361 de 1997, además de contraponerse a la discriminación laboral, atribuye beneficios a los empleadores que contribuyen a la inserción de personal discapacitado en sus empresas. El artículo 24 del mismo consagra garantías con el fin de incentivar el empleo de personas en condiciones de discapacidad. 
a) A que sean preferidos en igualdad de condiciones en los procesos de licitación, adjudicación y celebración de contratos, sean estos públicos o privados si estos tienen en sus nóminas por lo menos un mínimo del $10 \%$ de sus empleados en las condiciones de discapacidad enunciadas en la presente ley debidamente certificadas por la oficina de trabajo de la respectiva zona y contratados por lo menos con anterioridad a un año; igualmente deberán mantenerse por un lapso igual al de la contratación. (Ley 361, 1997)

Tener en la nómina un mínimo de $10 \%$ de personal en situación de discapacidad es ser prioridad para ser escogido en cualquier convocatoria pública o celebración de contratos con el Estado. Por tanto, el gobierno incentiva a la comunidad empresarial a integrar personal discapacitado para obtener ganancias y oportunidades contractuales.

b) Prelación en el otorgamiento de créditos subvenciones de organismos estatales, siempre y cuando estos se orienten al desarrollo de planes y programas que impliquen la participación activa y permanente de personas en situación de discapacidad. (Ley 361, 1997).

Los prestamos subvencionados, según el Portal Cliente Bancario - Banco de España, son créditos de interés inferior al del mercado, el cual una entidad estatal pone las condiciones para que la empresa aceda al préstamo. Por ende, el Estado otorga beneficios financieros a quienes incluyan laboralmente a personas en condición de discapacidad.

c) El Gobierno fijará las tasas arancelarias a la importación de maquinaria y equipo especialmente adoptados o destinados al manejo de personas en situación de discapacidad. El Gobierno clasificará y definirá el tipo de equipos que se consideran cubiertos por el beneficiario. (Ley 361, 1997)

Dado lo anterior, el Gobierno promueve el empleo de las personas en condiciones de discapacidad, acondicionando las necesidades de estas personas, permitiendo el acceso de los equipos y máquinas adecuadas para el desarrollo laboral de los discapacitados.

Artículo 31. Los empleadores que ocupen trabajadores en situación de discapacidad no inferior al $25 \%$ comprobada y que estén obligados a presentar declaración de renta y complementarios, tienen derecho a deducir de la renta el $200 \%$ del valor de los salarios y prestaciones sociales pagados durante el año o período gravable a los trabajadores en situación de discapacidad, mientras esta subsista.

PARÁGRAFO. La cuota de aprendices que está obligado a contratar el empleador se disminuirá en un $50 \%$, si los contratados por él son personas con discapacidad comprobada no inferior al $25 \%$. (Ley 361, 1997).

El gobierno establece múltiples estrategias para incentivar a los empleadores a que integren en sus nóminas personal discapacitado. Una estrategia novedosa son los beneficios tributarios que establece la ley 361 de 1997 en el artículo 31, el cual consagra que toda empresa que contrate personas discapacitadas no inferior del $25 \%$ de su 
discapacidad, tienen el derecho de deducir la renta el $200 \%$ de los salarios y prestaciones sociales durante el periodo de un año que subsista. Por ende, la contratación de personal discapacitado puede contraer ahorro tributario para las empresas, además de reducir la cuota de aprendices en un $50 \%$, es decir, contratar la mitad de aprendices de la cuota obligatoria.

Según el Pacto de Productividad, organización que brinda programas empresariales de promoción laboral para personas con discapacidad, además de los beneficios anteriores, establece otros que generan ventajas para las empresas;

Productividad: Las personas con discapacidad se encuentran a lo largo de su vida con muchas barreras. Encontrar una posibilidad laboral es para muchas de ellas la única oportunidad de demostrar todas sus competencias y potencialidades; este interés se convierte en un motivador para un alto nivel de productividad. (Pacto de productividad, 2018)

En otras palabras, las personas en condiciones de discapacidad tienden a valorar el empleo, puesto que en sus vidas se han presentado múltiples obstáculos, por ende, estas personas harán todo lo posible para demostrar sus capacidades y tener el mejor desempeño en el área laboral, lo que los hará sentir útiles y motivados. Todo lo anterior, genera en la empresa productividad.

Imagen corporativa: Una empresa que propone la lectura de un nuevo imaginario de los trabajadores con discapacidad, vinculándolos laboralmente bajo los criterios de igualdad, equidad y equiparación de oportunidades, se posiciona ante su entorno económico y social como una organización que asume sus responsabilidades y aporta al país. Demuestra su interés prioritario de contribuir al mejoramiento de la calidad de vida de sus ciudadanos, reconociendo y aceptando las diversas humanas como parte integral de los conceptos de crecimiento económico y desarrollo, aplicados por las nuevas sociedades del siglo XXI. (Pacto de productividad, 2018)

La inclusión laboral de personal discapacitado hace reconocimiento a las empresas como aquella organización que tiene responsabilidad social, que está comprometida con el desarrollo positivo de la ciudadanía, que antes de un interés económico contribuye con las necesidades de la sociedad y trabaja para mejorar la calidad de vida.

Desarrollo organizacional: La vinculación de personas con discapacidad a los procesos productivos de una empresa, les permite a los demás trabajadores reconocer al otro como diferente, convivir con la diferencia y aprender de ella; circunstancias que influyen en el cambio de referentes relacionados con la actitud, el comportamiento, la manera de asumir compromisos y responsabilidades, así como en la forma de ver y analizar reflexivamente su proyecto de vida y los imaginarios sociales existentes, frente a las reales características y potencialidades de las personas con discapacidad. (Pacto de productividad, 2018)

Incluir a personas discapacitadas en las plantas de trabajo permite que los demás trabajadores eliminen ideas discriminativas o de rechazo, pues es un ejemplo de vida, superación y convivencia que contribuye con el principio de solidaridad y responsabilidad social. 


\section{La aptitud laboral de las personas en condición de discapacidad, estrategias aplicadas en otros países}

Las personas en condiciones de discapacidad, a pesar de encontrarse en desventaja física o intelectual hacia las demás personas, quieren superarse y encontrar una razón para ser aceptadas en la sociedad a través de la educación y el empleo. Por tanto, al momento de tener acceso a un cargo laboral, la disposición en el trabajo se verá reflejada en demostrar sus competencias y habilidades. Además, querrán permanecer en el empleo, dado que por la circunstancias de sus vidas y las dificultades que se presentan en el entorno social, la permanencia en el empleo es un logro significativo y constituye una importante oportunidad para demostrar todo su potencial.

Por consiguiente, la Asociación Chilena de seguridad (ACHS) presenta un artículo llamado "Por qué Contratar Personas con Discapacidad", el cual manifiesta algunas aptitudes de las personas en condiciones de discapacidad que generan beneficios en las empresas. Entre ellas se resalta su eficiencia para realizar tareas específicas que van de la mano con su discapacidad,

(...). Ejemplos: las personas con discapacidad auditiva son ideales para trabajar en lugares de alto ruido sin sufrir daños que conlleven a enfermedades laborales por esa causa. Quienes tienen síndrome de Down desarrollan muy bien tareas repetitivas. Las personas con discapacidad físico-motora pueden hacer labores que requieren estar mucho tiempo en un solo lugar, y las personas con discapacidad visual trabajan mejor en lugares oscuros. (Asociación Chilena de Seguridad, 2014).

Por tanto, las personas en condición de discapacidad suelen tener destrezas especiales que a la larga generan ganancia y lealtad para las empresas, lo cual debe ser puesto en conocimiento a los empleadores. Por eso, en materia de la ley 361 de 1997, a pesar de contar con la protección y los incentivos económicos, es necesario implementar este tipo de beneficios que promueven recursos humanos, resaltando la competencia y el compromiso por parte del trabajador con discapacidad hacia el cargo laboral.

Por otro lado, las TIC son herramientas tecnológicas para la información y la comunicación. El uso de estas ha generado un fuerte impacto en la sociedad, dado que gracias a estos recursos tecnológicos ha sido posible el desarrollo de la educación, la cultura, la política y la opinión a través del internet. Con respecto a la discapacidad, la tecnología ha sido imperante, puesto que permite acortar distancias, estrechar lazos y sobre todo flexibiliza las actividades complejas, permitiendo así mejor desarrollo laboral de las personas con discapacidad. Por tal razón, su incidencia en el sector empresarial y laboral, como el teletrabajo, constituyen herramientas innovadoras para el empleo, que han permitido que, a través de la tecnología y la comunicación, se emprendan vínculos laborales a larga distancia. Esto es definido por el artículo 2 de la ley 1221 de 2008, el cual reza:

Teletrabajo. Es una forma de organización laboral que consiste en el desempeño de actividades remuneradas o prestación de servicios a terceros utilizando como soporte las tecnologías de la información y la comunicación - TIC para el contacto entre el trabajador y la empresa, sin requerirse la presencia física del trabajador en un sitio específico de trabajo. (Ley 1221, 2008) 
Como resultado, el teletrabajo ha sido un gran avance en el sector laboral, pues es una forma de integrar, vincular y estrechar lazos laborales mediante la tecnología de la información. Por tanto, se puede afirmar que el teletrabajo y el uso de las TIC serían una estrategia elemental para la inclusión laboral de personas con discapacidad, ya que el trabajo a distancia a través de la red brinda oportunidades de empleo, facilitando la comunicación sin necesidad de presencia física y actividades complejas. Este es un método laboral sencillo que abre las puertas a la inclusión.

Los beneficios de esta nueva forma de organización del trabajo se han puesto en manifiesto en numerosos informes: nuevas oportunidades para las regiones periféricas, aisladas y menos desarrolladas, ahorro de energía y menos contaminación, mayores posibilidades para trabajadores minusválidos, incremento de la productividad. (Thibault, 1998, p. 210)

Por ello, la ley 361 de 1997, que regula la protección laboral de la discapacidad, es transcendental que mencione el teletrabajo como estrategia innovadora para incluir personas con discapacidad en las empresas, ya que es una alternativa moderna que, de acuerdo con la tecnología, facilita las actividades complejas, permitiendo así un mejor rendimiento laboral por el trabajador con discapacidad.

Un ejemplo positivo por seguir sobre el tema de la inclusión laboral de personas con discapacidad es en el país de Argentina, que desde el año 1980 ha trabajado en el tema de la discapacidad intensamente, demostrando su compromiso y responsabilidad social ante las personas en condición de discapacidad. La Organización Iberoamericana de Seguridad Social (OISS) (2014) hace un estudio extenso sobre la discapacidad en varios países latinos, y entre ellos resalta a Argentina, que se determina como un país defensor de los derechos laborales de las personas con discapacidad. Por ejemplo, la ley 22.431 organiza el Sistema Integral de Protección de Personas con Discapacidad de forma general y acoge definiciones de educación, empleo y políticas públicas sobre la discapacidad. A través de esta ley argentina incluye a las personas en situación de discapacidad en la sociedad y cuenta con organismos responsables de la disertación de personas discapacitadas.

Además de ello, dicha ley ha permitido la creación de programas para la integración laboral de la discapacidad, como "Promover la Igualdad de Oportunidades de Empleo", "Programa Especial de Formación y Asistencia Técnica para el Trabajo para Trabajadores con Discapacidad" y "Programa de Inserción Laboral para Trabajadores con Discapacidad", entre otros. Uno muy novedoso es el "Programa de Empleo Independiente para Personas con Discapacidad", el cual fomenta el empleo autónomo de las personas con discapacidad. El programa ofrece un subsidio para que las personas con esta condición, mayores de edad, emprendan su propio negocio. Los mencionados programas tienen el objeto de proteger el acceso laboral de las personas en condiciones de discapacidad.

Un punto importante es que Argentina cuenta con una Oficina de Empleo para Personas con Discapacidad, el cual es un espacio al que las personas con discapacidad se acercan en busca de oferta laboral y a su vez las empresas en busca de personal discapacitado acuden a esta oficina con el objetivo de encontrar a una persona con discapacidad apta para el empleo. 
El factor que más caracteriza al Estado Nacional de Argentina es que tiene cuota obligatoria de reserva de puestos de empleo para las personas con discapacidad en los empleos públicos o empresas privadas. La cuota se estima del $4 \%$, es decir, las empresas privadas, empresas del Estado o los establecimientos de servicios públicos deben tener el $4 \%$ o más de personal con discapacidad sobre el total de los trabajadores de la empresa. Dichos puestos deben ser ocupados exclusivamente por personas en situación de discapacidad, como cualquier otra vacante, pero el aspirante debe estar capacitado para el empleo, sin discriminar su condición de discapacidad.

Finalmente, pese a que el Estado Colombiano cuenta con la protección de la ley 361 de 1997 que se encarga de la Protección a la Estabilidad Reforzada del discapacitado, se queda corta al promover e incentivar al mercado laboral la inclusión. Hay carencia de conocimiento, programas de integración, capacitación y estrategias para una debida integración de las personas con discapacidad al mundo laboral, además de un total desconocimiento de las habilidades y competencias laborales que pueden ofrecer este tipo de personas. También, falta la aplicación de la tecnología y las TIC como herramienta idónea para que, a través del teletrabajo, se emprendan vínculos laborales efectivos.

\section{Discusión}

Las condiciones especiales que poseen las personas en situación de discapacidad presuponen un desafío para las mismas y para el Estado, pues las relaciones sociales se ven desafiadas a adaptar modelos prestablecidos para suplir las necesidades de todos los colectivos y, en ese sentido, impulsar procesos que permitan la convivencia y adecuación de todos los actores diversos en un mismo contexto comunitario.

Este artículo de revisión doctrinal y normativa nos muestra como primer aparte que, en efecto, el trabajo es fundamental para la vida del hombre, por lo que la integración efectiva de nuestro grupo objeto de estudio es absolutamente indispensable para que se salvaguarden de manera plena sus derechos y se contribuya a una terapia de mejoramiento desde diferentes ámbitos, tal y como lo plantea Heron (2003). La misma Corte Constitucional se refiere a esta correlación entre las repercusiones sociales que rodean la discapacidad y la dependencia de ellos en virtud del entorno social. Esto se observa cuando la sentencia C-066 de 2013 expone que un medio social negativo puede convertir la discapacidad en invalidez y un medio social positivo permite mejorar la calidad de vida de las personas en condición de discapacidad. También, Brogna (2010) advierte que la situación de discapacidad está sujeta a la estructura social que crea ambientes y comunidades que excluyen las condiciones especiales de las personas en condición de discapacidad.

Investigaciones más recientes constatan que el problema de adaptación social general persiste en la generalidad de las sociedades. Muyor (2018) asegura que el problema de la discriminación solo puede superarse cuando se avance a un modelo de vida independiente, en el que converjan autonomías no solo físicas, sino también de representación y reivindicación de acción ciudadana, que constituya una autonomía moral. En virtud de todo lo anterior, se evidencia entonces que la discapacidad asumida como problemática debe verse desde una perspectiva social, que encuadre un proceso marco, concretado en repercusiones que trasciendan la esfera individual y choquen con el andamiaje colectivo de las sociedades contemporáneas. Estas no solo deben incluir en sus actividades regulares a un grupo poblacional con necesidades especiales, sino que también merecen una adaptación total de los entornos, no solo laborales, sino también 
educativos y de participación, para que no simplemente se incluyan, sino también se hagan parte de manera natural y positiva. Esto, por supuesto, implica que el ambiente laboral constituya un eje fundamental en la inclusión naturalizada del colectivo, pues la posibilidad de empleo impacta afirmativamente en la manera como la persona en condición de discapacidad se relaciona con su entorno directo y la percepción que se tiene de la funcionalidad de ese individuo para con la sociedad.

En atención al segundo objetivo, el marco jurídico internacional y nacional debe ser observado a la luz de los beneficios laborales y económicos tanto para el empleador como para el trabajador, en virtud de la vinculación laboral de personas con características físicas, psíquicas o sensoriales especiales. En primera medida, encontramos la protección constitucional, siendo Colombia un Estado Social de Derecho. El cumplimiento de su articulado debe traducirse en verdaderas políticas públicas de salvaguarda, situación que en la práctica no se evidencia de manera concreta, tal y como se expondrá a continuación. Si bien, los artículos 13, 47, 53 y 54 de la carta política nacional consagran una serie de prerrogativas de derechos que son la piedra angular de la responsabilidad estatal para con este colectivo, que van desde el reconocimiento a la protección de las personas que se encuentran en debilidad manifiesta (art.13), la obligación de adelantar políticas públicas que permitan la integración social (art. 47), el afamado Principio de la Estabilidad Laboral Reforzada (art. 53) y el derecho a las personas con condiciones especiales a un empleo acorde a sus necesidades (art. 54), la realidad es que la regulación principal que desarrolla estos preceptos, no es una herramienta que brinde suficiencia pública al problema de la inclusión efectiva.

Como se evidencia en el desarrollo del presente artículo, la Ley 361 de 1997 es el mecanismo legal que en la actualidad rige las políticas de inclusión social de las personas en condición de discapacidad, enfocado en diferentes componentes que, a juicio del legislador, permiten la integración plena y protección efectiva de derechos. Once y Manspower (2008) identifican como problemática de inclusión la falta de información de los empleadores respecto a ciertas limitaciones al momento de despedir y el desconocimiento de políticas de adaptabilidad en el empleo que no permiten la vinculación, haciéndose esta de manera obligatoria para cubrir cuotas y recibir beneficios económicos y tributarios. Esto indica que, sin los mismos, las empresas no se plantearían el contratar este tipo de personal. Por su parte, la tercerización laboral que abunda en nuestro Estado y la falta de inclusión a población discapacitada dentro de estas mismas empresas y bolsas de empleo, excluye de manera discriminatoria y directa cualquier posibilidad de éxito de una política pública enfocada en relaciones costo-beneficio.

Contrario sensu, investigaciones realizadas en el Estado de Manabí, Ecuador, por García et al. (2018) en el contexto ecuatoriano de esta comunidad en específico, demuestran una aprobación de las medidas adoptadas por el gobierno para la ejecución de políticas públicas de inclusión, encontrando solo un $20 \%$ de inconformidades o percepción de recrudecimiento del problema. Sin embargo, las motivaciones empresariales se repiten, toda vez que la indagación concluye en afirmar que las contrataciones se realizan para cumplir diversas cuotas, encontrando además una reticencia a la contratación por el costo corporativo de adaptar el ambiente de trabajo a la especialidad del trabajador. Este paralelo nos permite interpretar que las exenciones o beneficios tributarios no impulsan per se una voluntad real de apoyo al colectivo para su inclusión laboral de la parte de las empresas, pues lo más probable es que sin ellos, no se contemplaría por parte de los empleadores la contratación de estos trabajadores. Es por lo anterior que se recomienda que el Estado no solo brinde prerrogativas y exenciones, sino que también contribuya con 
el sector público y privado a la adaptabilidad de los espacios laborales, contribución económica que permite la reducción de los costos y el aumento de los beneficios para todas las partes implicadas en la relación laboral.

Ahora bien, analizando el artículo álgido de la ley 361 de 1997 que regula las relaciones laborales entre empleadores y trabajadores, el artículo 26 encuentra posiciones encontradas en torno a la conveniencia de su mandamiento y, sobre todo, si este constituye una extralimitación de la discriminación positiva, que en realidad no beneficia a ninguna de las partes de la relación laboral. Analizando el artículo, se determina la existencia de un conflicto jurídico, pues, pese a que la norma es clara, genera disparidad al momento de su aplicación, dado que no es lo mismo la discapacidad que se genera bajo una patología biológica (discapacidad cognitiva) y aquella discapacidad que es originada por el trabajador en el cumplimiento de sus funciones laborales que desarrolla pérdida de la capacidad laboral inferior al $50 \%$. Es decir, hay un trato similar en situaciones jurídicas diferentes, lo cual produce evidentemente una barrera que impide el acceso laboral a personas con discapacidad. En observancia de dos proyectos de ley y su exposición de motivos (proyecto de ley 129 de 2008 y proyecto de ley 018 de 2015), pese a sus intentos legislativos por reformar la ley 361 de 1997, no se ha logrado una salida del conflicto, puesto que no le ha sido posible al legislador dirimir este asunto de interpretación jurídica, lo que produce vacíos normativos $\mathrm{y}$, como consecuencia, confusión respecto a su aplicación. Toda esta problemática implica que los empleadores se cohíban de contratar a personas con discapacidad y el acceso laboral de las mismas.

Diferentes organizaciones como el Consejo Gremial Nacional y la Fundown Caribe manifiestan su apoyo a la posibilidad de eliminar el requisito de la aprobación del Ministerio del Trabajo para el despido, limitando su aplicación solo cuando se quiera despedir por razones propias de su discapacidad, apelando al principio de buena fe. Mientras que otras como Sintrametal no contemplan esa posibilidad, pues temen que se desmejoren las condiciones de los trabajadores con necesidades especiales, por lo que se aumentaría la discriminación y la desvinculación masiva de este grupo poblacional. Si bien no existen estudios de campo que presenten datos reales de las consecuencias derivadas de este cambio legal, no se puede desconocer que el artículo es claro, que la posición de las personas en condición de discapacidad es absolutamente desventajosa y aprovechable para los intereses económicos de las empresas, y que además las limitaciones para el despido arbitrario constituyen pieza fundamental en la salvaguarda de sus intereses con un enfoque diferencial.

Finalmente, se pudo evidenciar que existe una aptitud laboral especial que puede ser ventajosa para ciertos oficios ideales para personas en condición de discapacidad. Además, la adopción de nuevas tecnologías facilita las actividades laborales que, en otros contextos, serían muy dificultosas para adaptarlas a un empleo factible en virtud de ciertas limitaciones físicas y psíquicas de personas del colectivo. Las nuevas leyes que regulan la relación entre tecnología y trabajo, como la Ley 1221 (Ley del Teletrabajo), se queda corta en implementar herramientas metodológicas y funcionales que amplíen el espectro laboral a individuos con capacidades diferenciales. También es evidente que los esfuerzos realizados por el Estado no se comparan con las políticas de inclusión de otras naciones, en vista de que los beneficios aplicados aquí han sido ineficaces a la hora de brindar un porcentaje concreto y satisfactorio a la inclusión al empleo y la vida laboral de las personas en condición de discapacidad. 


\section{Conclusiones}

Luego de realizar el anterior estudio sobre los factores que impiden la contratación laboral de personas con discapacidad, inicialmente es menester afirmar que el rechazo laboral hacia las personas en situación de discapacidad es una realidad, sea por causas sociales o jurídicas.

La ley 361 de 1997 permite la estabilidad laboral reforzada del trabajador en condición de debilidad, sin embargo, pese a que la norma es clara, se genera un conflicto jurídico al momento de su aplicación en la sociedad, lo que ha ocasionado que los empleadores desconozcan el mundo de la discapacidad y, por consiguiente, no permitan el acceso laboral a esta comunidad. A los empleadores, autoridades y la sociedad les falta interés respecto a la problemática, debido a que los empleadores no plantean la posibilidad de nuevos perfiles en sus empresas y lo ventajoso que puede ser en el mercado laboral incluir en sus nóminas personal con discapacidad. En cuanto a las autoridades, no asumen la discapacidad como un problema real, ya que solo se limitan a crear normas que eviten la discriminación, pero no políticas públicas que resuelvan el conflicto jurídico que ocasiona el artículo 26 de la ley 361 de 1997 al momento de su aplicación. Finalmente, la sociedad, ha creado prejuicios hacia estas personas, excluyéndolos de participar en actividades diarias, creando barreras que imposibilitan un debido desarrollo y rehabilitación por parte de las personas con discapacidad.

Las personas en condición de discapacidad tienen derecho a la educación, a la libre escogencia de profesión y al acceso laboral indiscriminadamente, por tanto, todos los colombianos deben acoger a estas personas y procurar que su participación política, cultural y social sea activa, a través de un trabajo digno y trato igualitario.

Respecto al análisis de la investigación, se tienen algunas recomendaciones para la inclusión laboral de las personas en condición de discapacidad:

Primero. El mecanismo de inclusión laboral de las personas con discapacidad. La ley 361 de 1997 debe ser reformada, no para derogar la estabilidad laboral reforzada, sino para resolver el conflicto jurídico entre las personas con discapacidad cognitiva y las personas que adquieren la discapacidad durante el ejercicio laboral.

Segundo. Es necesaria la creación e implementación de políticas públicas por parte de las autoridades, encaminadas a promover las oportunidades de empleo en las personas con discapacidad.

Tercero. Eliminar el requisito de la autorización del Ministerio de Trabajo en cuanto al despido de las personas con discapacidad no es una solución para la problemática del acceso laboral, ya que esta autoridad debe impedir que se dé una discriminación en el vínculo laboral. Es importante la autonomía de los empleadores con sus trabajadores, pero debe existir el seguimiento que evite los abusos.

Cuarto. Agregar un nuevo título en el Código Sustantivo del Trabajo el cual reglamente las relaciones laborales con personas en situación de discapacidad para suplir vacíos jurídicos y promover el acceso laboral de personas en condición de discapacidad.

Quinto. Aplicar el uso de las TIC y el teletrabajo como elemento innovador tecnológico que crea vínculos laborales entre el empleador y el trabajador con discapacidad sin necesidad de actividades complejas. 
Finalmente, la integración de las personas con discapacidad no solo es deber de las autoridades nacionales e internacionales, pues también es responsabilidad de la sociedad. Adicionalmente, se propone facilitar el desarrollo profesional y educativo de estas personas, es decir, que para una efectiva adaptación es necesario que la sociedad tenga en cuenta a estas personas en todas las actividades diarias, acceso a los establecimientos y voz en las decisiones importantes.

\section{Agradecimientos}

Quiero agradecer a Dios porque está presente en cada paso que doy, día a día me da fortaleza para no desistir. En segundo lugar, a mi madre porque siempre cree en mí y es mi apoyo constante. Mis agradecimientos a Noriana Franco quien por su conocimiento y guía fueron claves para la realización de este trabajo, gracias por sus consejos y dedicación. Por último, gracias a cada una de las personas que fueron motivación y aliento que me ayudaron a hacer posible este proyecto.

\section{Referencias}

Asamblea General de las Naciones Unidas. (10 de diciembre de 1948) Declaración Universal de los Derechos Humanos. Resolución 217 A (III).

Asamblea General de las Naciones Unidas. (13 de diciembre de 2006) Convención sobre los derechos de las personas con discapacidad.

Asamblea General de las Naciones Unidas. (4 de marzo de 1994) Normas uniformes sobre la igualdad de oportunidades para las personas con discapacidad. A/RES/48/96.

Asociación Chilena de Discapacidad (2014) Por qué contratar personas con discapacidad. [Entrada de blog]. Recuperado de http://www.achs.cl/portal/ACHS-Corporativo/newsletters/pymes-achs-aldia/Paginas/Por-que-contratar-a-personas-condiscapacidad.aspx\#.XAmjX2hKjIV.

Barton, L. (2008). Superar las barreras de la discapacidad. Ediciones Morata. Recuperado https://books.google.es/books?hl=es\&lr=\&id=CZpyAgAAQBAJ\&oi=fnd\&pg=P A107\&dq=modelo+social+de+discapacidad\&ots=snZMG6NBYD\&sig=Zve4p6zTnkBHkCS2-wwpHOLTI8\#v=snippet $\& \mathrm{q}=$ oliver $\& \mathrm{f}=$ false.

Best Buddies Colombia (2018) Abrir caminos hacia la integración social y laboral de las personas con discapacidad intelectual en el país. Recuperado de http://www.bestbuddies.com.co/

Brogna, P. (2010). Posición de discapacidad: los aportes de la Convención. SRE, México.

Colombia Digital (2018) Conceptos TIC. [Entrada de Blog]. Recuperado de https://colombiadigital.net/actualidad/articulos-informativos/conceptos-tic.html

Conferencia Internacional del Trabajo (20 de junio de 1983) Convenio sobre la readaptación profesional y el empleo (personas inválidas). Entrada en vigor: 20 de junio de 1985. Número 159.

Consejo Gremial Nacional. (1 de diciembre de 2015) Consideraciones al proyecto de ley por la cual se promueve el acceso al trabajo para personas con discapacidad y se dictan otras disposiciones. Ref. 064/2015.

Constitución política de Colombia [Const.] (1991) 2da Ed. Legis.

Convención Interamericana para la Eliminación de todas las Formas de Discriminación contra las Personas con Discapacidad. (7 de junio de 1999). Guatemala.

Corte Constitucional de Colombia. (10 de mayo de 2000) Sentencia C-531/2000 [MP Álvaro Tafur Galvis]. 
Corte Constitucional de Colombia. (11 de febrero de 2013) Sentencia C-066/2013 [MP Jorge Ivan Palacio Palacio].

Corte Constitucional de Colombia. (12 de mayo de 2017) Sentencia T-317/2017 [MP Antonio José Lizarazo Ocampo].

Corte Constitucional de Colombia. (12 de mayo de 2017) Sentencia T-317/2017 [MP Antonio José Lizarazo Ocampo].

Corte Constitucional de Colombia. (16 de marzo de 2006) Sentencia T-198/2006 [MP Marco Gerardo Monroy Cabra].

Corte Constitucional de Colombia. (18 de enero de 2011) Sentencia T-021/2011 [MP Luis Ernesto Vargas Silva].

Corte Constitucional de Colombia. (21 de agosto 2008) Sentencia T-812/2008 [MP Jaime Córdoba Triviño].

Corte Constitucional de Colombia. (26 de junio de 2003) Sentencia T-519/2003 [MP Marco Gerardo Monroy Cabra].

Corte Constitucional de Colombia. (26 de septiembre de 2012) Sentencia C-744/2012 [MP Nilson Pinilla Pinilla].

Corte Constitucional de Colombia. (30 de mayo de 1996) Sentencia SU- 296/1996 [MP Vladimiro Naranjo Meza].

Corte Constitucional de Colombia. (30 de mayo de 2012) Sentencia T-271/212 [MP Nelson Pinilla Pinilla].

Corte Constitucional de Colombia. (4 de noviembre de 2004) Sentencia T-1095/2004 [MP Manuel José Cepeda Espinoza].

Corte Constitucional de Colombia. (7 de julio de 1995) Sentencia C-255/1995 [MP Jorge Arango Mejia].

Corte Constitucional de Colombia. (7 de mayo de 2008) Sentencia T-434/2008 [MP Jaime Córdoba Triviño].

Corte Suprema de Justicia, Sala de Casación Laboral. (27 de enero de 2010) Sentencia R 37514. [MP Luis Javier Osorio López].

Engels, F. (1975). El papel del trabajo en la transformación del mono en hombre. Andreus.

Fundación Once y Manpower, F. (2008). Perspectivas del mundo empresarial, respecto a la contratación de personas con discapacidad. [Informe]. Madrid: Autor.

Fundown Caribe (23 de octubre de 2015) Consideraciones al proyecto de ley por la cual se promueve el acceso al trabajo para personas con discapacidad y se dictan otras disposiciones. Ref. 064/2015.

García. J, Cedeño. M. y Cobacango. L. (2018). Accesibilidad laboral de las personas con discapacidad en las empresas públicas de la Parroquia Calceta Cantón Bolívar. Revista Caribeña de Ciencias Sociales (abril 2018). Recuperado de //www.eumed.net/rev/caribe/2018/04/accesibilidad-laboral-discapacidad.html.

Heron, R. (2003). Cómo ayudar a las personas discapacitadas a encontrar un empleo: guía práctica. International Labour Organization.

Ley 1145 (2007) Por medio de la cual se organiza el Sistema Nacional de Discapacidad y se dictan otras disposiciones. Diario Oficial: 46.685.

Ley 1221 (2008) Por la cual se establecen normas para promover y regular el Teletrabajo y se dictan otras disposiciones. Diario Oficial: 47.052.

Ley 1346 (2009) Convención sobre los derechos de las personas con discapacidad. Diario Oficial: 47.427.

Ley 361 (1997) Por la cual se establecen mecanismos de integración social de las personas en situación de discapacidad y se dictan otras disposiciones. Diario Oficial: 42.978 . 
Ley 762 (2002) Convención Interamericana para la Eliminación de todas las Formas de Discriminación contra las Personas con Discapacidad. Diario Oficial: 44.889.

Ley Estatutaria 1618 (2013) Por medio de la cual se establecen las disposiciones para garantizar el pleno ejercicio de los derechos de las personas con discapacidad. Diario Oficial: 48.717.

Marx, K. y Engels, F. (1974). La ideología alemana. Barcelona: Ediciones Grijalbo S.A, Montevideo: Ediciones Pueblos Unidos. Recuperado de https://teoriaevolutiva.files.wordpress.com/2013/10/marx-k-la-ideologc3adaalemana.pdf.

OISS. (2014). Medidas para la promoción del empleo de personas con discapacidad en Iberoamérica. Revista Española de Discapacidad 2(1), 239-242.

Organización Mundial de la Salud y Organización Panamericana de la Salud. (2001). CIF: Clasificación internacional del funcionamiento, de la discapacidad y de la salud. Organización Mundial de la Salud. Recuperado de http://www.imserso.es/InterPresent2/groups/imserso/documents/binario/435cif.p df.

Pacto de productividad (2018) Programa empresarial de promoción laboral para personas con discapacidad. Recuperado de http://www.pactodeproductividad.com/empresasinclusivas/beneficios/beneficios-para-las-empresas.

Pérez B. (2016) Derecho laboral, seguridad social y la empresa. Biblioteca Jurídica Diké. ISBN: 978-958-731-157-0.

Proyecto de Ley 018 (2015). Por la cual se promueve el acceso al trabajo para personas con discapacidad y se dictan otras disposiciones.

Proyecto de Ley 129 (2018) Por medio de la cual se modifica la Ley 361 del 7 de febrero de 1997 por la cual se establecen mecanismos de integración social de las personas con limitación.

Rodríguez, J. M. (2019). Nuevos significados de la discapacidad: De la igualdad de capacidades a la igualdad de derechos. Acciones e investigaciones sociales, (39), 33-55.

Salazar, C. (2007). El Teletrabajo como aporte a la inserción laboral de personas con discapacidad en Chile: Una gran carretera virtual por recorrer. Teletrabajo, 9(25), 89. Recuperado https://www.researchgate.net/profile/Cristian_Salazar/publication/325463720_El _Teletrabajo_Como_Aporte_a_la_Insercion_Laboral_de_Personas_con_Discapa cidad_en_Chile_Una_Gran_Carretera_Virtual_por_Recorrer/links/5b0f53550f7e 9b1ed7036ff5/El-Teletrabajo-Como-Aporte-a-la-Insercion-Laboral-de-Personascon-Discapacidad-en-Chile-Una-Gran-Carretera-Virtual-por-Recorrer.pdf.

Sintrametal (17 de noviembre de 2015) Consideraciones al proyecto de ley por la cual se promueve el acceso al trabajo para personas con discapacidad y se dictan otras disposiciones. Ref. 064/2015.

Taboada. B. (2018). Efectos tributarios en la contratación de personas con discapacidad por parte de empresas del sector privado (Trabajo de investigación parcial).

Thibault, J. (1998). Teletrabajo: ¿retorno al pasado o esperanza de futuro? Cuarta Mesa De Trabajo: El Teletrabajo. Zaragoza. Recuperado de http://www.unizar.es/centros/eues/html/archivos/temporales/08_AIS/AIS_08_ 